\title{
Covid-19 Enters College but to What Degree?
}

\author{
Christopher Willard
}

\section{Degrees of Response}

It is becoming clear that the Covid-19 pandemic and consequent lockdown raised midsemester havoc in higher education. Face-to-face courses were shifted to online delivery, often within a week's notice as faculty and administrators scrambled to save the semester. (See, e.g., Impelli, 2020). Employees were tasked to work remotely while students undertook online learning, some for the first time. Many universities abandoned letter grades and switched to a credit/no credit scheme. Such changes were not without pushback. Students petitioned to have A-F grades back, while other students petitioned for the credit/no credit scheme. According to an article in MarketWatch, as of this writing, at least 100 lawsuits have been filed across the United States by students seeking tuition refunds (Kesher, 2020).

Meanwhile, forward-looking discussions in academia began to revolve around the possibility of some or all Fall semester courses delivered online. The California State University system made the decision to put much of their Fall semester course offerings online; in contrast, Purdue University announced it intends to hold face-to-face classes, at least until the Thanksgiving break. Quickly identified in discussions were equipment and connectivity needs, course delivery needs, and the means to allow quick approval of courses requiring changes in order to run wholly online. Lab and studio-based courses demanded particular consideration, such as a revised course content or limited access to facilities. Discussions also focused on student needs, including those of low-income students and those of students with disabilities. Although many schools scrambled, synchronous and asynchronous forms of online learning are not new. Faculty have often utilized their university's particular learning management platform such as Blackboard, Canvas, Moodle, or D2L. Sites offering online courses like edX, Coursera, and FutureLearn are widely known (there are many more) and in fact MOOCs (Massive open online courses) are booming according to Steve Lohr at The New York Times. (Lorh, 2020). In MOOC models, courses are often free, although learners may purchase a certificate of successful completion.

Cathy O'Neil, who says she has taught online-only for 16 years, suggests in a recent opinion piece that as a result of the pandemic, the value of a traditional, formal, face-to-face education, will be questioned. The author suggests that "online education should come at an online price" and that because of this reevaluation, "college will never be the same" (Oneil, 2020). I tend to agree. When free courses are offered, many of which offer job-relevant, performative skills, it is easy to see why a student whose focus is obtaining a job might question a multi-thousand dollar education offering a credential but which in a bleak job market may be perceived to result in a job the same as they might have gotten without the degree.

However, before digging into these issues, I need to state the empathetic position that I 
think we all share. Faculty were and continue to be supportive of governmental and institutional interests in maintaining the well-being of its community members. The abolishment of grades in favor of a credit/no credit scheme for the first semester of 2020 was considered an empathetic response to students whose semester was upended without warning. Many of these students had the additional stress of moving and having to abandon personal items left in dorms or at the university, all while continuing their courses online. It must be acknowledged that many people rose to these unexpected challenges with flexibility, compassion, and support.

On the other hand, the responses to Covid-19 inside ivory tower meeting rooms may be described as a mess. Numerous institutions advanced new emergency measures, often without much-supporting evidence, that often were enacted following non-standard routes of approval. At times, such measures contradicted existing agreements, policies, and procedures. The rationale generally went something like this, "We need to put this into place immediately because of the crisis." Then, in my view, the politicization of the pandemic found on mainstream media in the United States entered into academia with the result of both polarizing and shutting down debate about proposed emergency measures. The phrase "We're all in this together" effectively put any dissenter on notice that to vote against a proposed emergency measure was to announce one's lack of empathy. So much for the sort of viewpoint diversity and parrhesia that is supposedly a hallmark of higher education.

My train of thought in considering the impact of Covid-19 on higher education situates pandemic responses within the currently existing neoliberal saturation of life, government, and market, and that has more and more shoulder-butted education to conform with its agenda. Consequently, I see educational responses to the pandemic acknowledging more of an intensification of existing neoliberal pressures on education than as signaling new pressures from the pandemic alone.

The outline of my discussion takes the following frame: Empathetic responses in a time of crisis should not necessarily entail the infringement of or the abandonment of rights articulated in existing policies, procedures, collective agreements, or contracts. I say this thinking of a cautionary by Alan Brinkley, "Every major crisis in our history has led to abridgments of personal liberty, some of them are inevitable and justified. But in most such crises, governments have also used the seriousness of their mission to seize powers far in excess of what the emergency requires" (Brinkley, 2006). If anything, responses to the Covid-19 pandemic have highlighted a misalignment between management rights as perceived by university administrators and faculty rights, and it is here I wish to direct my focus. Areas of particular vulnerability include academic freedom, faculty workload, and intellectual property.

Crisis responses created and disseminated by university administrators, often with little or no consultation with faculty or faculty unions, potentially have long term ramifications and therefore, such responses must, and I don't use that word lightly, be points of overt discussion in academic bodies. Even in cases where there are valid assertions of management rights, I still suggest that a requirement to discuss is necessary, if indeed as said, we are all in this together. Finally, I shift to a considering that academic changes intensified by the pandemic, which include shifts to online learning, mimic a neoliberal movement toward a gig economy. This has, at least, according to Nicole Kobie even before the world knew of Covid-19, a potential for long term educational impact (Kobie, 2018). The short-term solution is to go with existing technologies and forms of delivery. Yet as we move forward, particularly in light of this sudden massive shift to online learning, it will be necessary to engage in discussions about what the most effective form of learning looks like and how that might dovetail with current formal educational learning structures.

\section{Now and Forever?}

Reasonable and responsible responses do not mean immediate voting in of emergency 
measures that run roughshod over existing agreements, policies, procedures, and contracts. According to behavioral scientist Rachel McCoy who considered the reasons people focused on wearing masks versus other practices, "the actions we take to regain a sense of control tend to be the least effective for controlling the virus" (McCoy, 2020). She cites examples of bulk buying, the wearing of face masks by healthy people, and the improper wearing of face masks. In her view, these actions provide individuals with a better sense of control in a time of uncertainty, more so than does the proven preventative of frequent and careful handwashing. This sense of perceived control with respect to academic decisions around Covid-19 could affect the type of emergency measures that are proposed and enacted. Meetings filled with people who offered bewildered shrugs ended with agreement upon actions, without detailed research and evidence, proving that the action was the most effective response. Combine this with the current social media mindset of cancel culture, in which opposing views are simply canceled, most explicitly evidenced by censorship and banning on social media like Twitter, Facebook, and Reddit, and a foundation is set for quick fixes that are best perceived as controlling the uncertainty.

For example, one might ask whether moving courses online is simply a new method of delivering content. Jonathan Zimmerman points out that studies in the 1990s found little difference in the achievement of students whether they took online, hybrid, or face-to-face courses. However, he also cites a 2014 study by Columbia University researchers who looked at 40,000 students in community and technical colleges in Washington State to compare how the same students did in online courses versus face-to-face courses. The researchers found that all students performed worse in the online courses, affecting particularly hard those with less academic opportunity and skill. In Zimmerman's view, we have a duty to find out the efficacy of online courses. He writes, "So far as I know, no college has committed to using this crisis to determine what our students actually learn when we teach them online" (Zimmerman, 2020). In his opinion, going forward without this information is not simply "a lost opportunity; it's a violation of our most sacred trust." (Zimmerman, 2020). Or, for example, we might ask, what exactly was the research-based rationale to prove that abolishing grades for a credit/no credit scheme was best practice in a crisis? The fact that students started petitions to both have the choice of grades and credit/no credit belies the idea there was consensus or that rational, research-based evidence for the decision was made available to students. The scenario of Fall 2020, in which some institutions are compelling their entire student body to take online courses, is the perfect opportunity to gather evidence and to measure student online learning as compared to face-to-face learning, according to Zimmerman.

Over the first few months of 2020, I became aware of numerous emergency responses to Covid-19 at various North American institutions that were said to contravene normal policies and procedures. In addition, a number of these were initiated without limitations, and therein lies the possibility of any temporary measure to become chronic. An example would be a written change to a policy or procedure, stated in voting meetings as temporary, but which lacks any start and end date. A response by administrators about how they might need to use the emergency measure again in the future, at will, and thus it should not have an end date, should be viewed as unreasonable. In the event of a new crisis, another document can be created with a new set of effective dates. Professor Shannon Dea, Vice-President of the faculty association of the University of Waterloo said, "Universities started by reacting to the emergency. Next, they will settle into a new phase of medium-term measures until we're beyond the crisis. Finally, they will have to adapt to the new normal, whatever that looks like" (Dea, 2020). Faculty agree to quickly enacted emergency measures that require immediate implementation, but they may not have the opportunity, or time, to fully consider the long term impact of each measure. Potentially then, a set of documents is in play that may be cited as setting precedent for future use.

Some of the changes in the universities came down from the government. The view of Michael Murphy is that emergency rules have given powers to the executive beyond common checks and balances and the temptation will be to cling to those powers. He speaks of government, but the same threat may exist with a university's senior administration. The danger, 
writes Murphy, is that universities will end up with less autonomy. Many institutions already find this is happening, for example, with government-issued key performance indicators. Some of these apparently strive to turn system-wide programs into trade school models with foci on graduate employment, apprenticeships, job transition, and the commercialization of intellectual property (See, e.g., Anderson, 2020). Combine this with cuts to funding and institutions without substantial endowments are doomed to comply. One example is the internationally known 150 year-old San Francisco Art Institute, which is not accepting any students for the Fall 2020 semester, and has announced plans to close, substantially downsize, or partner with another institution. The institute's President, Gordon Knox said the already declining financial situation had been exacerbated by the coronavirus pandemic (Wells, 2020). A broader view is taken by Brian Rosenberg, who wonders if colleges generally will be resilient enough to bear the long term financial cost of the lockdown (Rosenberg, 2020).

\section{Freedom In and From Academia}

Academic freedom is generally granted to faculty so that they can teach their courses in any manner they wish, normally restrained by approved learner outcomes and university logistics. Resultantly, content, design, pacing, methods, means of delivery, assessment, evaluation, and the assignment of grades are the responsibility of faculty.

The movement to online course content delivery resulted in institutions who did not already have a robust online presence to quickly move current courses online. Some late spring and summer courses were put online. However, in some institutions, the creation of an online course asks that a different set of creation conditions apply, conditions specifying aspects such as recordings, ownership of intellectual property, and so forth. This potentially results in semantic wrangling in which an online course is said to differ from a course in which the delivery method is solely online. To state the obvious, a course is comprised of content and content delivery methods, and both should exist as the purview of the faculty. Arguably the decision by administrators to move courses online technically violates the faculty member's right to the type of content delivery that they deem most effective. Faculty, obviously and for good reasons, agreed to this emergency shift in delivery method. If this issue is pursued and indeed going online with an existing course is simply a method of delivery, and fully within the faculty member's academic freedom, it would suggest that a faculty member could run a course online at will; it is hard to imagine that administrators would agree to this move.

Many administrators quickly stated they would abrogate grades for the semester, citing that the decision was an empathetic response to students whose routine was suddenly filled with change and uncertainty. The result was that administrators decided letter grades would be replaced by a credit/no credit grading scheme, or that students had the option of choosing either a letter grade or a credit/no credit. This decision gave students control over the type of grade they wanted, and often this meant that they could negotiate their grade with an administrator. For example, a student receiving any passing grade, no matter how low, could ask for and receive a grade of "credit" without any consultation on anyone's part with the course instructor of record. At issue is the right of faculty to assess and assign grades. Indeed, they are the only people (perhaps in addition to Teachers' Assistants) who have an awareness of each student's progress toward and fulfillment of stated learner outcomes. Wresting grading from the responsibility of faculty should be seen as an unacceptable encroachment of academic freedom.

Finally, planning for a Fall 2020 semester online, in part or in whole, has caused some institutions to see as beneficial some degree of consistency in either course content or delivery. Institutions may be requesting that sections of the same course be taught the same, with the same design, content, methods, pacing, and so forth. Or faculty may be asked to create video lectures designed to be used by faculty teaching different sections of the same course. Doug Lederman, in an article for Inside Higher Ed, stated that going on line "also calls for greater dependence 
on predeveloped instructional materials (freely available open educational resources, pre-existing course libraries such as those developed by massive open online course providers" (Lederman, 2020). MOOCs are one model in that the same content can be accessed by many people over multiple years, but administrators need to be aware that academic freedom in the university also means that content created by a faculty member is for the discrete course they are teaching. It is the property of the faculty member and most often has not been created for distribution at the will of either administrators or other faculty.

The exception will be work-for-hire, in which a faculty member is hired by the institution to create a course for distribution. This, in turn, necessitates a contract that fully articulates all foreseeable conditions of rights, distribution, and payment. It should also be noted that at some institutions, this form of work-for-hire would set up a new category of employment, that in turn, would touch a collective agreement, normally requiring approval by faculty. Lederman, citing Richard Garrett who wrote a report on reimagining the college experience for a possible fall of online delivery wrote, "He also suggests that campus administrators and instructors may need a 'new compact' on a more centralized and systematized approach to course development, rather than leaving the building of courses up to each faculty member's own preferences on structure and format. That may make many faculty members bristle, but 'it is definitely necessary' in a moment like this, Garrett said" (Lederman, 2020). A problematic model in most current academic structures, although it is possible to imagine, would be a university undertaking a workfor-hire contract for a course that as a video allows the course to be "taught" by someone with a title such as course administrator, thus taking the course out of faculty teaching responsibility.

Advocated is the view that faculty have, or should have, a respected voice in determining policies and practices with respect to distance education, that articulate ownership of material they create for courses, face to face, and online. Faculty must be clear that normal development of course material is not work for hire. The faculty teaching online courses should have academic freedom, to use their own material, not to be forced to share their material without agreement and compensation, and not be forced to use material created by someone else. Other more specific guidelines and nuances of the guidelines mentioned here, such as material prepared by a content expert and "unbundled" by faculty facilitators, are found in the document (Euben, 2020).

Again, future crisis practices should not be allowed to disregard current agreements. Changes such as these are potentially incremental attacks on academic freedom and should be perceived as such, no matter the intended benefit.

Finally, but worth remembering in a cancel culture environment is that academic freedom in its best form in academia gives faculty the right to criticize without deference any institutional prescribed doctrine in the search for knowledge and best practice. Academic freedom does not require that faculty must simply accept last-minute decisions handed down from on high during a sudden lockdown, and especially during a future of more online delivery of course content.

\section{When Working Hard Isn't Working Well}

A balance of faculty duties typically includes activities specified by a collective agreement that includes teaching, service to the institution, and research/research dissemination. A clause also usually exists that states other duties may be assigned at the pleasure of a named senior administrator. Depending upon the institution, the embedding of course revision and creation may be understood as part of a normal workload, or a course release may be given for the time required to undertake the work of significantly revising or creating a new course. Measures in response to sudden online delivery have likely interrupted normal workloads, in that faculty whose courses have not been created specifically as online courses have been or will be expected to get their courses into an online deliverable form. This, in and of itself, takes hours and days of work. One faculty member complained on a Reddit forum about being "told to prep our fall 
courses to be online only, in person only, AND a mix of both" (u/Superfluous, 2020) As the Redditor pointed out, the request is to design three courses with the same content, with equal information, assignments, and so forth. In this manner, workload as a direct result of responses to Covid-19 substantially increases, potentially without recognition or compensation or without a relaxation of other service work.

It should be seen as unreasonable to ask that faculty do uncompensated institutional work off contract or during the time allocated for other duties. Typically, for many faculty, little research can be done during the teaching semester due to the workload. They are entitled to their allocated yearly leave (summer or otherwise), and they must schedule their research into their remaining time. The assigning of extra work to accommodate online delivery can potentially impede upon vacation or research time, as though faculty are required to donate that time to the institution in an exceptional time.

Faculty and their unions should be particularly wary of pressure, real or perceived, to undertake uncompensated labor. The issue of uncompensated labor is magnified with job-precarious hires, part-time faculty, in particular. They are normally off contract over the summer, and they return to contract normally one or two weeks before the first day of classes. Their ability to catch up with online delivery of their courses in such a short time raises concerns. This group could also be vulnerable to informal requests to undertake unpaid labor over the summer, for example, in the sense individuals might believe their rehiring will be contingent upon doing the work. Their hiring to teach an online course might be contingent upon their agreeing to use their own capital resources for equipment and internet connectivity. A related issue of faculty concern is class size. If in response to governmental mandates about social distancing, face-to-face lab classes, for example, could be split into multiple smaller sections with the expectation the faculty member teach all sections while considering the aggregate of the sections to be only one course. On the other hand, going online with a course could see its numbers drastically increased. Clear language in collective agreements about numbers of courses taught, or numbers of students in courses becomes important.

All of this seems to move education closer to a neoliberal, gig economy mentality. The idea, 'Everyone's an entrepreneur!' is word spinning to support a series of actions that rely upon non-institutional capital and unpaid labor for the completion of tasks. These should be subjects of concern and rebuke that go hand in hand with the idea that a university may also function as a coercive institution, with implied pressures often as effective as directives. Again, this is especially true for faculty whose job security is precarious.

\section{Who Owns the Future}

The devil is in the details appears in full bloom with intellectual property (IP) that brings up a panoply of specific points requiring discussion and agreement in the academic setting. There are however, a few general arenas that frame the subject.

It is common that the university owns a course description (a brief descriptive paragraph of the course), learner outcomes (normally passed through academic bodies), and an outline of the course that states things like times, credit weight, and other general information. Most universities agree that faculty own their course syllabi, course design, lectures, presentations, specific methods for delivering specific content, and so forth. Copyright laws generally support this too. That said, copyright laws vary depending on the country but it's common to find that any work created and fixed in a tangible form is automatically copyrighted to the creator. Frequently copyright exists without the creator adding a statement of copyright, without self-copyright mailing of documents to oneself, without the need for a (C) symbol, and without a need to register the work with a copyright office. Checking with national copyright laws is important as some countries do require a copyright symbol. Obviously, applying any of these copyright standards would provide extra precaution. Copyright normally includes anything fixed in a tangible form, 
such as audiovisual work, written work, paintings, computer programs, and so forth. As such, the written and online work that faculty create for a course would be covered. I suggest it is important that faculty recognize their course material as work created in a fixed and tangible form, that is the result of our experience, knowledge, and creativity.

Intellectual property rights should be retained by faculty when courses move to online delivery, although nuances related to ownership can vary. Faculty will want to differentiate between work for hire, in which the faculty member is commissioned by the university to create course materials for the university that is not the normal creation of course material. In a work for hire scenario there should be a contract that articulates aspects such as royalties, sharing or transferring, author crediting, licensing agreements, internal or external use allowances, and so forth. It should also be clear that the teaching of a course in the classroom, or the running of such courses on a university hosted platform, should not constitute a common contract phrase about substantial use of university resources in creating the course, thus giving rights to the university. This brings up a related point for consideration, that a document articulating the creation of courses specify that faculty are to be the creators, to prevent external non-faculty entities from creating deliverable course content. It is worth watching for documents and language that contravene a creator's ownership of content created for online delivery, distance learning, and/or MOOCs without a work for hire agreement (AAUP, n.d., Intellectual Property). Another good document is found with the Canadian Association of University Teachers (CAUT, 2013).

A second issue to consider concerns the online dissemination of content. Michael Poliakoff draws attention to the fact that there potentially exists "a permanent record of virtually everything" that would be part of an online course (Poliakoff, 2020). We know that information posted online can be saved, copied, and recorded in many forms, often by a linked or external device. In turn, this perpetual existence could stifle free and open dialogue, and it could potentially negatively impact academic freedom and student learning. One deterrent might be to add language about copyright and a prohibition against unauthorized recording into course syllabi, rather than to simply rely on a university document if any, that students may not have access to. The University of California at Santa Cruz has developed some good language that might be seen as a model for this (Lee, 2020). A view that faculty own their IP rights that informs a series of questions are found in an article by Edward Maloney and Joshua Kim (2019) who state broadly, "every college and university would be wise to affirm principles of faculty control of and access to the intellectual property created for teaching." Ideally, this would be language in a collective agreement or policy. From another viewpoint, the university student code of conduct could address unauthorized recording and/or the distribution of lectures. A document that outlines protections for students and faculty in online courses would seem ethically important regarding image ownership and privacy laws. Even a scenario of universal access is balanced by creator rights, the need to incentivize all stakeholders, and framed by regulatory policies, limitations, and exceptions (Vézina and Green, 2020).

A leader in considerations of proprietary rights and protections for faculty has been The American Association of University Professors (AAUP) that advocates for clarity in applicable documents. In their view, "The administration should publish these policies and procedures and distribute them, along with requisite information about copyright law, to all concerned persons. The policies should include provisions for compensating those who create new course materials or who adapt course materials originally prepared for traditional classroom usage, including any use or reuse of recorded material." As well, the document references its Statement of Principles on Academic Freedom and Tenure endorsed by more than 200 education and professional organizations (AAUP).

\section{Gig-Learning}

As mentioned before, I see many of the changes enacted or proposed in higher education as a 
result of the pandemic as an intensification of neoliberal ambitions. It is a multi-pronged pressure as governmentally mandated key performance indicators linking funding to enrollment numbers, retention, graduation rates, and nearly immediate job placement, that together reflect a shift toward a technocratic society. Jason Read describes this movement clearly, "The contemporary trend away from long term labor contracts, towards temporary and part-time labor, is not only an effective economic strategy, freeing corporations from contracts and the expensive commitments of health care and other benefits, but it is also an effective strategy of subjectification as well. It encourages workers to see themselves not as "workers" in a political sense, who have something to gain through solidarity and collective organization, but as 'companies of one.' They become individuals for whom every action, from taking courses on a new computer software application to having their teeth whitened, can be considered an investment in human capital" (Read, 2009). Undoubtedly, there are benefits to a model in which learners have more agency in creating individualized learning pathways. On the other hand, it is worrying that education has the potential to promote education as simply job skill preparation and that meaning in education is narrowed to consuming and exchange. The result is a knowledge economy centered on educating labor for service industries and their managers. In the view of Ilkka Kauppinen, knowledge capitalism means more and more that the outcomes of post-secondary formal learning institutions are at the behest of capitalist desires (Kauppinen, 2013). In the capitalist model of education, there is a reproduction of the social relations found with a gig economy. These are often promoted as stressing flexible work time and task management, a work/life balance, and greater independence, when alongside is the fact that gig workers discover job precariousness, a lack of benefits, lower salaries, and longer working hours (Duszynski, 2020).

An ad for an online dance lesson company writes, "Learn to dance for only $\$ 8.25$ a month. ....access anywhere...Start leveling up now and don't be left behind" (Steezy, 2020). Perhaps this indicates one future of education beyond brick and mortar buildings. No longer are there courses but levels, with zero face-to-face contact hours. Learning becomes fractured in which micro-learners attain micro-credentials in micro-steps. Air Ph.D. anyone?

This sort of "gig learning" confronts traditional learning models in the sense that the ondemand consuming of video lectures (granted online learning is more than this) mimics features of gig economy social behaviors and mindsets. Outcomes arguably might include the general passivity of the learner, the idea that knowledge is easily accessed and easily consumed, the one-way direction of learning, the blurring of learner and consumer, the lack of discourse and challenge, a diminishment of the individualized learning path, a dismissal of inquiry-based learning, an enhancement of a power differential, and a reinforcement of a producer/consumer relationship. All of this works to potentially stifle academic freedom, not with a direct attack on knowledge but through its form positioning knowledge as a step by step acquisition of performative and instrumentalist skills as opposed to knowledge and expertise rich instructors who ask for a sustained investigation, or a questioning attitude.

Peter Janzow uses the cute little euphemism "soloists" to describe gig workers. "A decade from now, when solo workers comprise the majority of the American workforce, I think it will be common for all of us to point to digital credentials and badges as a better way to talk about our own expertise and the know-how of others. Trusted digital credentials will strengthen the new economy by removing some of the high-frequency friction and inefficiencies of project work. Digital, verifiable credentials owned by each worker will ease employer uncertainty while forming project teams. And at the same time, badges will help each of us to identify relevant new work projects and navigate toward just-in-time learning opportunities" (Janzow, 2015). Here is found a manifestation of the capitalist predation. One might seriously question that the general goal of education in society is to reduce friction between thinkers, workers, and the businesses that need work done.

Brancaleone and O'Brien speak to the "the appearance of learning outcomes (via its messages of 'transparency', 'visibility', 'assess-ability') remains key to its concrete (economic) value for education. The media remains largely complicit in this education spectacle through an 
unproblematic acceptance of the learning outcome" (Brancaleone and O’Brien, 2011, p. 510). To be clear, the learning outcomes the authors speak of are not simply those arising from the pursuit of knowledge; instead, they align with external agendas in which education is putatively only of short term instrumental value. Performance indicators stress seamless transitions into jobs related to majors without recognizing the lack of jobs in more than a few domains. The humanities is one of the better examples. There are few if any jobs that allow one to do the work they did in their major. There are few if any jobs that allow a philosophy major to further a metaphysical argument, a visual artist to create a neo-conceptual sculpture, a literary major to write a contemporary novel, or a composer to write their own symphony. Instead, these humanities majors obtain service jobs, working as a guard in a museum, doing gig design, serving coffee at Starbucks and so on, jobs unrelated to their education. Clearly, the government's need to instrumentalist education at the expense of certain domains has been ongoing. Brancaleone and O'Brien continue, "The dynamic of the Bologna Process reveals the unquestioned adoption of the market model of education and mirrors the railroading of the neoliberal agenda and inscription into economic policy across the European Union since the 1990s....What remains particularly worrying is that market policy has extended its sphere of influence, in direct and indirect ways, to all other areas of society, including education" (Brancaleone and O'Brien, 2011, p. 515-516). It is as though each learner is, upon receiving a credential, required to immediately shift to being a social laborer, operating within an exchange economy, acting as though the aphoristic "knowledge for the sake of knowledge" is simply history.

Arguably, as a result of this process, we lose learners who have a wide range of ways and means of responding to the world, we lose viewpoint diversity, and we lose critical and analytical thinking. Also lost are reflection, empathy, negotiation, and new meaning creation that result in more sophisticated knowledge.

Gig-learning supports students as they learn to rely upon the technocratic architecture of corporate structures and on-demand, task-specific assignments. Governments don't seem to care about what's lost in holding educational institutions to key performance indicators in their perpetual seeking of an answer to the short term question, "Where's the value-added or payoff?" It is a sad irony that in promoting a gig economy that it is the gig workers (temporary faculty) who are first to be let go when financial cuts come to education.

As I've argued, responses to the pandemic generally seem reflective of neoliberal goals that strive to commodify and marketize nearly every aspect of life, that privileges competition and individual rationality. As this mindset continues to enter into academia, core educational values are at stake. According to Daniel Saunders and Blanco Ramírez (2016), "If critical scholars focus on particular manifestations of excellence as problematic without challenging excellence as normative neoliberal technology, they risk delving into a technical argument about the 'proper' measurement and assessment of excellence. Such an argument works to strengthen and legitimize the normative power of excellence and its undergirding neoliberal ideology." Excellence is a vague term and one that, if used without reference, can be applied to virtually any mandated structure that is backed up by metrics designed to support a cost/benefit rationale.

\section{Beyond this Pandemic}

The pandemic has forefront a range of issues particular to and which have the potential to touch upon academic freedom, intellectual property, workload, and a furthering of neoliberal agendas. That said, I do not mean to present the issues as one-sided. There is a great deal of potential and value in global open-source learning, open access publishing, and so forth, to shift traditional models of knowledge acquisition and dissemination that would be of great benefit to many. My goal is to suggest wariness in the face of pandemic changes spun as emergency measures, sold as temporary, which are silently turned more permanent. To a degree, the symbolic order of education was collapsed by the pandemic, lockdowns, and movement to online course 
delivery. I think it is fair to say that we won't simply return to the old order, nor will we suddenly create a new model, rather our future will be built upon a foundation of adaptations to the crisis responses.

The exceptional can quickly become normative. The issues outlined above potentially can, inch by inch, pave the way for both administrative control and loss of faculty rights. Of course, faculty wish to be empathetic, and we want to assist in helping our community, but we shouldn't be seduced or cowed into relinquishing often hard-won rights. I always imagine when a precedent is initiated the phrase a year or two later being stated in a meeting, "When it was first implemented, you didn't object."

Not only do conversations around the issues become important, but it is also often necessary to make explicit that a duty to consult involves substantive discourse (Consultation Principles, 2018). With respect to existing policies or collective agreements, there is benefit in the drafting of a letter of understanding that speaks to both the changes and the time period that such changes would be active. 


\section{References}

Anderson, Drew. January 20, 2020. "Alberta post-secondary funding will be tied to performance." CBC News.

AAUP. N.d. "Intellectual Property Issues for Faculty and Faculty Unions.” www.aaup.org/sites/default/files/intellectual_property_issues_faculty.pdf. Accessed May 27, 2020.

Brancaleone, David and O'Brien, Stephen. 2011. "Educational commodification and the (economic) sign value of learning outcomes." British Journal of Sociology of Education. 32 (4): 501-519.

Brinkley, Alan. 2006. "Civil Liberties in Times of Crisis. Bulletin of the American Academy." 26-29. www.amacad. org/sites/default/files/media/document/2018-12/ Civil\%20Liberties\%20in\%20Times\%20of\%20Crisis.pdf. Accessed May 20. 2020.

CAUT. 2013. "Guidelines for the Use of Copyrighted Materials”. https://d3n8a8pro7vhmx.cloudfront.net/ caut/pages/2924/attachments/original/1510862882/ Low-Res-Guidelines-for-use-of-copyrighted-material. pdf?1510862882. Accessed May 28, 2020.

https://assets.publishing.service.gov.uk/government/ uploads/system/uploads/attachment_data/file/691383/ Consultation_Principles__1_.pdf. "Consultation Principles.” 2018. Accessed May 31, 2020.

Dea, Shannon. April 16, 2020. "University shutdowns bring new challenges to academic freedom.” University World News. Africa Edition.

Duszynski, Maciej. April 22, 2020. "Gig Economy: Definition, Statistics \& Trends [2020 Update].” https:// zety.com/blog/gig-economy-statistics?gclid=CjwKCAjw7-P1BRA2EiwAXoPWA6AHVepcAfwXw-Dc3ph2YmocX3U9yCbleIbK5KK7chnzWEv1XGFNhBoClCgQAvD_BwE. Accessed May 14, 2020.

Euben, Donna. 2020. "Faculty Rights and Responsibilities in Distance Learning. Distance Learning and Intellectual Property: Ownership and Related Faculty Rights and Responsibilities." www.aaup.org/faculty-rights-and-responsibilities-distance-learning-2000. Accessed May 16, 2020.
Impelli, Matthew. March 10, 2020. "All the U.S. Colleges and Universities That Have Cancelled In-person Classes Over Coronavirus Outbreak.” Newsweek. www.newsweek.com/all-us-colleges-universities-that-have-canceled-person-classes-over-coronavirus-outbreak-1491538. Accessed May, 21, 2020.

Janzow, Peter. October 14, 2015. "The Rise of the 'Solo Economy' - What it Means for Workers and Credentials. Pearson, Higher Education.” www. pearsoned.com/the-rise-of-the-solo-economy-what-itmeans-for-workers-and-credentials/. Accessed May 17, 2020.

Kauppinen, Ilkla. 2013. "Different Meanings of 'Knowledge as Commodity' in the Context of Higher Education." Critical Sociology. 0(0): 1-17.

Kesher, Andrew. May 22, 2020. "At least 100 lawsuits have been filed by students seeking college refunds and they open some thorny questions." MarketWatch. www.marketwatch.com/story/unprecedented-lawsuits-from-students-suing-colleges-amid-the-coronavirus-outbreak-raise-3-thorny-questions-for-higher-education-2020-05-21. Accessed May 25, 2020.

Kobie, Nicole. September 14, 2018. "What is the gig economy and why is it so controversial?" Wired. www. wired.co.uk/article/what-is-the-gig-economy-meaningdefinition-why-is-it-called-gig-economy. Accessed May 15,2020 .

Lee, Herbert. March 19, 2020. "Intellectual property and copyright in course materials during COVID-19 remote teaching: information and language for instructors." Newscenter, UC Santa Cruz. https://news. ucsc.edu/2020/03/intellectual-property-and-copyright-in-course-materials-during-covid-19-remote-teaching.html. Accessed May 20, 2020.

Lederman, Doug. May 14, 2020. "In Inside Higher Ed, A Playbook for a Second-Choice Fall.” Inside Higher Ed. Accessed May 14, 2020.

Lohr, Steve. May 26, 2020. Remember the MOOCs? After near-death, they're booming. The New York Times. 
Maloney, Edward and Kim, Joshua. June 12, 2019. "Intellectual Property and Digital Learning: Developing a Campus Strategy.” Inside Higher Ed.

McCoy, Rachel. March 14, 2020. "How to Worry Better." New Scientist. 245 (3273): 23.

Murphy, Michael. May 2, 1010. "Universities beyond the coronavirus crisis - What awaits?” University World News.

O’Neil, Cathy. May 25, 2020. "Covid-19 Will Make Colleges Prove Their Worth.” Bloomberg. www. bloomberg.com/opinion/articles/2020-05-25/covid19-will-make-colleges-prove-their-worth. Accessed May 25, 2020.

Poliakoff, Michael. April 21, 2020. "What Will COVID-19 Mean For Academic Freedom?” Forbes.

Read, Jason. 2009, "A Genealogy of Homo-Economicus: Neoliberalism and the Production of Subjectivity." Foucault Studies. 6: 25-36.

Steezy.co. 2020. reddit.com. Accessed May 27, 2020.

Rosenberg, Brian. April 10, 2020. "Will the cornovirus kill liberal arts colleges?” Times Higher Education.

Saunders, Daniel and Blanco Ramírez, Gerardo. November 16, 2016. "Against 'teaching excellence': ideology, commodification, and enabling the neoliberalization of postsecondary education." Teaching in Higher Education. 22:(4): 396-407.

u/Superfluous. May 22, 2020. Reddit, r/professors. www. reddit.com/r/Professors/comments/gol86x weve_ been_told_to_prep_our_fall_courses_to_be/. Accessed May 22, 2020.

Vézina, Brigitte and Green, Cable. March 31, 2020. "Education in Times of Crisis and Beyond: Maximizing Copyright Flexibilities.” Creative Commons. https://creativecommons.org/2020/03/31/education-in-times-of-crisis-and-beyond-maximizing-copyright-flexibilities/. Accessed May 22, 2020.

Wells, Madeline. March 24, 2020. San Francisco Art Institute likely to close due to coronavirus impact. SFGate.
Zimmerman, Jonathan. March 15, 2020. "Coronavirus and the Great Online-Learning Experiment.” Chronicle of Higher Education. 66:25: 10. 